\title{
Research and Practice of Talents Training Mode and Curriculum System of Marine Pharmacy
}

\author{
Qu Youle \\ Zhejiang Ocean University \\ Zhoushan, Zhejiang 316022 China \\ youle1060@163.com
}

\begin{abstract}
The talents training mode and the reform and innovation of curriculum system in institutions of higher learning are both the key and difficult part of teaching reform and ultimate goals of the reform of talents training mode. In recent years, focused on the requirements of talents training of marine pharmacy in emerging strategic industries, and centered on students' development which puts the all-round development, personality and potential development of students as the core, this paper thoroughly analyzes and applies the existing talents training mode and curriculum system of marine pharmacy to create distinctive talents training mode and curriculum system, which sheds light on the talents training in our country's marine pharmacy.
\end{abstract}

Keywords-marine pharmacy talents, training mode, curriculum system

\section{INTRODUCTION}

As one of the seven strategic emerging industries in our country, marine pharmacy (including marine biopharmacy) has huge potential and great demand for high-quality applied and innovative talents. Therefore, it is imperative for oceanographic institutions of higher learning to cultivate and develop talents of marine pharmacy in strategic emerging industries.

Affiliated to Zhejiang province, Zhejiang Ocean University is the only oceanographic institutions of higher learning in the industry, which is established for the sea, developed by the sea and thrives depending on the sea. It is known as "the cradle of marine talents". With the rapid development of institutions of higher learning in our country, it is urgent for colleges and universities to resolve such problems as the disappearance of specialized features caused by general education, the lack of learning motivation brought by popular education and the decrease of the practical and comprehensive applied ability resulted from diversified education.

\section{CONDENSE CONCEPT AND HIGHLIGHT CHARACTERISTICS}

Aiming to the fact of one of the seven strategic emerging industries in our country and the characteristics of huge potentials and great demand for high-quality applied and innovative talents, the educational concept we summarize for marine pharmacy and marine biopharmacy is to strengthen marine characteristic, coordinate colleges and enterprises to cultivate students and focus on potential development.

Therefore, starting from setting up new major of pharmacy,

Fund program: educational reform of Zhejiang province Reform and Innovation on Curriculum system for talents training and Teaching Content of Marine Pharmacy we have planned in advance to establish the objective of our university which is characterized by marine pharmacy and aims at serving strategic emerging industries in order to emphasize the cultivation of applied talents with innovative awareness. Particularly, with the approval of The planning of the development of marine economy in Zhejiang demonstration zone and The planning of new district of Zhoushan archipelago of Zhejiang, the development of marine economy of Zhejiang has become national strategy, which marks the new stage of the development of marine economy in Zhejiang. And marine biopharmaceutical industry, as a strategic emerging industry, has become one of key industries of the development of marine economy in Zhejing and Zhoushan, which requires lots of talents of marine pharmacy.

In recent years, we unremittingly explore the talents training mode of marine pharmacy and the research on the optimization of curriculum system. The general framework of "two kinds of earliness" (that is students engage in scientific research in early stage and enterprises participate in the formulation of training program in early time), "three processes" (that is tutorial system in the whole process, quality control in the whole process and integration of theory and practice in the whole process), talents training mode featuring "one kind of running through" ( that is scientific research runs through the whole process of teaching) and the curriculum system of "trinity" ( that is the demand of industrial development, the demand of enterprise competence and the demand of professional practice of double abilities on innovation and entrepreneurship) has been formulated. Based on knowledge imparting and centered on ability cultivation, such framework focuses on the coordinated development among knowledge, ability and quality and endows talents with stronger practical and innovational abilities and professional skills. More than 1000 innovational and applied talents of marine pharmacy are cultivated for marine biopharmaceutical industry.

\section{INNOVATE TRAINING MODE AND OPTIMIZE CURRICULUM} SYSTEM

\section{A. "Distinctive" talents training mode of marine pharmacy}

Talents training mode is a systematical framework which reflects educational concepts and includes all important factors involving talents training. Based on the talents training mode and research on the optimization of curriculum system of 
educational programming projects of Zhejiang, we combine strategic emerging industries to research the objectives, situations and trend of high-skilled talent demand and explore connotation elements, operational mode and evaluation system of current talent training mode of pharmacy from the perspective of regional economic development. And we also conduct theoretical analysis and empirical research from macro, medium and micro aspects. Centered on the questions of "'What kind of people we should train, who and how to train them", we highlight the characteristics and focus on the exploration and application of talents training mode of marine pharmacy

In the past ten years, we have always focused on students' development and paid attention to the development of students' potentials as well as individuality. We have regarded the comprehensive physical and mental development of students together with the personality, potential development as the starting point of reformation, newly reformed and innovated the traditional pharmacy talents training mode, and set the improvement of students' innovative awareness and ability as the fundamental goal. We have successively explored the "early participation of students in scientific research in order to enhance innovative ability", introduced the school-enterprise coordination cultivation mechanism on "the formulation of talents training program is to have enterprises involved in advance, " implemented the four-year system of " tutorial system in the whole process", brought in the concept of quality control in the whole process in pharmaceutical industry, strengthened the" control of teaching quality in the whole process ", adopted the mode of "integration of theory and practice in the whole process as well as project-based teaching ", and carried out the training mode of marine pharmacy talents such as feed-back teaching of " scientific research runs through the whole teaching process ", etc. Moreover, it has formed the talents training model framework of "two kinds of earliness" (that is students engage in scientific research in early stage and enterprises participate in the formulation of training program in early time), "three processes" (that is tutorial system in the whole process, quality control in the whole process and integration of theory and practice in the whole process), talents training mode featuring "one kind of running through" ( that is scientific research runs through the whole process of teaching) .This model framework focuses on the development of students' potential and personality.

First, starting from "tutorial system in the whole process". We change the role of teachers as authorities and monopolies of knowledge into the "students' tutor". In the beginning of freshman admission, each 4-5 students will be provided with a tutor. The tutor will adopt the four-year system, and take the improvement of students' innovative quality, practical ability, physical and mental development as well as the promotion of the sustainable development of students as the main line, and will fully instruct students in their choice of courses, social practice, production practice, scientific research practice along with scientific research and innovation, etc..

Second, starting from "early participation in scientific research," and liberating students from single infusion of books. Namely, each teacher's scientific research subject in pharmacy must absorb 3-4 students above the second grade as assistants to ensure that those students with ability and interest can enter the research practice in the early stage and participate in the research projects of teachers, so as to enhance students' sense and ability of innovation.

Third, strengthening the cooperation between schools and enterprises, and promoting school-enterprise coordinative cultivation. Confronted with many problems in existing higher education, we put forward the talent training concept of "Orientation into industry, cooperation between schools and enterprises, coordinative cultivation" and start from the "coordinative cultivation from both school and enterprise", build the school-enterprise coordinative cultivation leadership team. Based on the formulation of talents training programs, enterprises should be involved in advance to break through the closed-campus training model. Also, we build the talent training system on school-enterprise coordinative cultivation, and transformed from focusing on the subject theory teaching to school-enterprise coordinative education concept which emphasizes practice, thus deep cooperation between school and enterprise has been realized, and enterprises have truly participated in teaching. Also, the problems of production practice together with internship divorced from enterprise reality have been solved.

Fourth, starting from the teaching process. Students, teachers, parents, society, schools and enterprises should be jointly involved in the implementation. Through the evaluation mechanism of teaching quality management (such as supervision and student evaluation), the monitoring mechanism (such as class-attending by leaders or chiefs.), organizational security system (three levels of guarantee: Academic Affairs Office, College, Department), management system (various school regulations), information feedback system (students, mentors, teacher in charge of one class), rigorous process monitoring system as well as strict assessment evaluation system, the expected goal of teaching quality control in the whole process is achieved, and the improvement of teaching quality can be insured.

Fifth, starting from the project-based teaching, and implementing the integration of theory and practice in the whole process. We have successively carried out various subdirections of pharmacy specialty, as well as research on project-based teaching, and proceeded from the integration of theory and practice in the whole process and project-based teaching. We have applied the project-based teaching method in classes of Pharmacology, Drug Chemistry. For example, in the course of Marine Pharmacology, students are divided into a number of groups. Under the premise of theoretical study, students of each group arrange, collaborate and finish a complete theoretical and experimental process of sampling, active ingredient extraction, separation and testing. Students consciously work overtime, and each student has been trained to improve the theoretical and practical ability.

Sixth, it is prevalent that teachers pay more attention to scientific research over teaching in higher education. Teaching and scientific research are the two pillars of higher education, and as to how to properly handle the relationship between the two sides in practical work, we start from setting up an "open laboratory", and applying various scientific research 
achievements and projects. Each year we select students above the second grade with scientific research interest, among whom 5-10 students will form a group and regardless of different grades. Meanwhile, teachers in their spare time will carry out seminars to guide students how to use their spare time, and with the support of teachers' scientific research funds, students are instructed to carry out scientific research and subject reporting (such as new seedling plan, undergraduates 'innovative research, academic competitions, etc.). By means of this, we finally realize the true sense of scientific research and feed-back teaching, and the scientific research can run throughout the whole teaching process.

The reformation and innovation of the training mode in our college have achieved good results. Pharmacy graduates achieve the initial employment rate of $96.7 \%$, and counterpart employment rate of $90.5 \%$; postgraduate enrollment rate reaches more than 20\%; business satisfaction with the pharmacy graduates amounts to $95.6 \%$. 168 students have participated in and presided over more than 40 items, including national college students innovative projects, provincial new seedling plan, college innovative practices, and have won 10 national patents; 200 more students have participated in over 50 teacher research projects, and above 100 students have attended open scientific research practice, and published more than 100 papers, among which 12 papers are include by SCI / EI. In kinds of events at all levels, students have won more than 50 times. China Science and Technology once reported the advanced experience of the marine pharmacy teaching team through "Training Model of Innovative Marine Pharmacy Talents ".

\section{B. Curriculum system of marine pharmacy talents under "Integration between school and enterprise"}

Under the guidance of the education philosophy of "thick foundation, wide range, strong ability and high quality", according to the demand for highly-skilled talents in marine economy and strategic emerging industries, and based on the talents cultivation orientation of pharmacy specialty with the features of rich connotation, wide extension and comprehensive interdisciplinary courses, pharmacy specialty, in the past ten years, has always adhered to the professional cultivation guideline of "facing social needs, highlighting marine features, jointing emerging industries, strengthening practice training, and improving comprehensive quality". We have successively revised the teaching plan for three times, constantly optimized the curriculum system, updated the teaching content and optimized the curriculum structure. At last, we have formed the curriculum system of "trinity" (that is the demand of industrial development, the demand of enterprise competence and the demand of professional practice of double abilities on innovation and entrepreneurship) and the cultivation mechanism of "integration of school and enterprise", rebuilt the structure of teaching content in accordance with the ability and quality training objectives, and established the reformation goals of modular curriculum system.

The salient features of optimized curriculum system are: first, to expand the specialty direction and broaden the specialty range. In order to expand students 'choices, interest in learning and creativity, the Department of Pharmacy sets up three divisions: marine medicine, pharmaceutical engineering (marine biomedicine) and pharmaceutical marketing. Therefore, the professional range is broadened and the specialty structure is characterized by its openness. Second, in order to broaden the students' knowledge and form a reasonable knowledge structure, we have closely combine the strategic emerging industries in the curriculum system design, cooperated with the enterprises, and introduced the urgently-needed courses on marine pharmacy like Marine Pharmacology, Marine Biopharmaceutical Products. Meanwhile, in order to enable students to have more space for curriculum choices based on their own interests and career planning, and have more opportunities for the development of their physical and mental health, elective courses will be greatly increased, and the proportion of professional core compulsory courses, specialized courses and major electives is controlled at around 1: 1: 1 (excluding public basic courses, subject basic courses, general education courses). Third, in order to highlight the cultivation and training of students 'application ability, and to have talent cultivation more socially adaptable, the proportion of practice teaching is greatly increased in the curriculum system, and the practice teaching is not less than $35 \%$ of the total credits (hours) .On the basis of independent "teaching process of intensive time", according to the needs of enterprises, school creatively sets a total of four weeks of "college students innovation and entrepreneurship practice " at short periods in the first, second and third grade, in order to enhance the cultivation of students' innovation and entrepreneurship.

In order to ensure that the above-mentioned curriculum system is carried out effectively and orderly, the related infrastructure should be intensified. Firstly, the construction of curriculum should be strengthened and the complete and scientific curriculum database should be built. Such database stores detailed archival data of all courses about pharmacy and biopharmacy, including syllabus of every course, records of previous courses, teaching evaluation conducted by students, and curriculum contents and teaching schedule suggested by lectures.

Secondly, construction in laboratory and practical place should be intensified and a good platform for practical teaching should be actively built. We make full use of the special funds of Zhejiang to build experimental branches of marine pharmacy, the central finance to build synthetic laboratories of marine biopharmacy and construction projects such as key disciplines of marine biopharmacy of Zhejiang, engineering center of marine biopharmaceutical products of Zhejiang to build training platforms such as " practical training of separation and detection of marine biological products", "pharmaceutical training of marina biopharmacy(officinal microbial metabolic engineering, recombinase engineering and biotransformation, research and development of marine pharmaceutical resources and development of new drugs)" respectively. 16 stable colleges-enterprises integration of practical bases have been built, which make the number of teaching experimental projects undertaken by the platforms rise to $40.4 \%$, $44.3 \%$ experimental projects improved, the launching rate reach $100 \%$ and the rate of integrity and designability in professional experiments increase to over $80 \%$. 


\section{THE EFFECT OF "FRUITFUL" TEACHING REFORM}

Since the construction of pharmaceutical major, achievements have been made in talents training mode and the research of the optimization of curriculum system of marine pharmacy after decades of exploration and practice. We obtained provincial teaching research projects, the projects of class teaching reform and 10 programs of school-level teaching reform successively. And we edited over 10 textbooks or monographs. In 2008, marine pharmacology gained the award of school-level high-quality curriculum and was considered as the excellence in the examination of the construction of new majors in Zhejiang. In 2009, pharmaceutical major was built as school-level key discipline. In 2010, we were awarded as school-level innovative teaching team of marine pharmacy. And in the same year, pharmaceutical major was named as pilot zone for cultivating innovative talents of marine pharmacy in the college. In 2011, the research center of marine pharmacy of Zhejiang was built and engineering center of marine biomedical products of Zhejiang was approved. In 2012 , it was awarded as the key discipline of marine biopharmacy in Zhejiang and key discipline of pharmacy in Zhejiang Ocean University. In 2013, biopharmaceutical major was established. In 2014, pharmaceutical major was awarded as a distinctive major in Zhejiang. And in the same year, our team was awarded by Zhejiang Ocean University as excellent teaching team and excellent scientific research and innovative team.

\section{APPLICATION AND DEMONSTRATION}

Based on talents training mode and the construction of curriculum system, this study has achieved breakthrough and innovation in the cultivation of concept and mode, curriculum system and cooperation between colleges and enterprises.

\section{A. Transform concept and establish the concept of talents training characterized by focusing on students' potential development and personality development.}

Such concept embodies the characteristics of the times and is the core concept of talents training, which runs through the whole process of the teaching reform of talents training. From the perspective of design, this concept is conducive to inspire students' specialty and personality. For example, we can guide those students who are good at manual tasks to focus on experimental study and develop their potential on scientific research in order to highlight their innovative ability. We can make those students who are good at studying pay much attention to improve theoretical level and postgraduate qualifying examination rate in order to highlight their potential in further study.

\section{B. The general framework of the talents training mode} featuring "two kinds of earliness", "three processes" and "one kind of running through" and curriculum system characterized by "trinity" are established

The general framework is that students engage in scientific research in early stage and enterprises participate in the formulation of training program in early time, that tutorial system in the whole process, quality control in the whole process and integration of theory and practice in the whole process, that scientific research runs through the whole process of teaching, and that the demand of industrial development, the demand of enterprise competence and the demand of professional practice of double abilities on innovation and entrepreneurship. By diversified talents training mode and curriculum system relating to reality, students' knowledge, ability and quality obtain all-round development.

\section{Professional practical teaching system of "two innovative platforms and double abilities" is established.}

Relying on the characteristics and advantages of marine biopharmaceutical research, professional practical teaching system of "two innovative platforms and double abilities" in marine pharmacy engineering is established. Professional characteristics and advantages is highlighted, training plan is revised again, single experiments affiliated to curriculum are integrated, " and projects such as "professional basic experiment", "professional comprehensive experiment", "professional experiments on innovation and creating business", "professional comprehensive experiment for optional courses" and "scientific research and innovational practice" are added. Meanwhile, according to the need of industrial development, training bases outside college are expanded. And we sign contract with Zhejiang Xianju Pharma and other 17 pharmaceutical enterprises, hospitals, institutions for medicine inspection inside and outside province to set up bases to undertake the tasks of students' extracurricular training and enterprise training. The laboratory in the midst of coalition in Zhoushan has provided conditions for innovational outcome transferring into products.

The prominent characteristic of this research is that the layout of professional development has taken initial shape in the complementary between traditional advantages and emerging disciplines, cooperative mechanism between colleges and enterprises that serves the development of local economy and society and meets the needs of industries has been established basically and the optimization level of faculty structure has been significantly improved, which have promoted the rapid development of the profession.

\section{REFERENCES}

[1] Qu Youle. Research and Practice of Training Mode of the Applied Talents of the Ocean Medicine[J]Pharmaceutical Education, 2006,22(1):1-3

[2] Gan Chunji, Li Jinyu, Xie Miao. Practice of the Management in Opening Public Laboratory[J]Research and Exploration in Laboratory, 2005,24(1):83-86

[3] Wang Yan, Wen Hong, Zhang Xuenong. Practice and Exploration of the Tutorial System for Pharmaceutical Undergradutes[J] Pharmaceutical Education. 2011, 27 (4) : 14-16.

[4] Feng Zhihua, Xu Juntian, Zhang Bingzhi, et al. Research on the Cultivation of Scientific Research Quality of Undergraduates of Marine Science Major[J]Science and Technology Innovation Herald. 2010,32:169. 